\title{
Coupled Methyl Group Rotation in FMN Radicals Revealed by Selective Deuterium Labeling
}

- Supporting Information -

Richard Brosi,${ }^{\dagger}$ Boris Illarionov, ${ }^{\ddagger}$ Lorenz Heidinger,${ }^{\S}$ Ryu-Ryun Kim, ${ }^{\ddagger}$ Markus Fischer, ${ }^{\ddagger}$ Stefan Weber, ${ }^{\S}$ Adelbert Bacher, ${ }^{\dagger}\|\|$ Robert Bittl ${ }^{\dagger}$ and Erik Schleicher* ${ }^{\S}$

${ }^{\dagger}$ Freie Universität Berlin, Fachbereich Physik, Institut für Experimentalphysik, Arnimallee 14, 14195 Berlin, Germany.

*Universität Hamburg, Institut für Lebensmittelchemie, Grindelallee 117, 20146 Hamburg, Germany.

${ }^{\S}$ Albert-Ludwigs-Universität Freiburg, Institut für Physikalische Chemie, Albertstr. 21, 79104 Freiburg, Germany.

" Fakultät für Chemie, Technische Universität München, Lichtenbergstr. 4, 80247 Garching, Germany 


\section{A) Supporting Information for ENDOR spectroscopy}

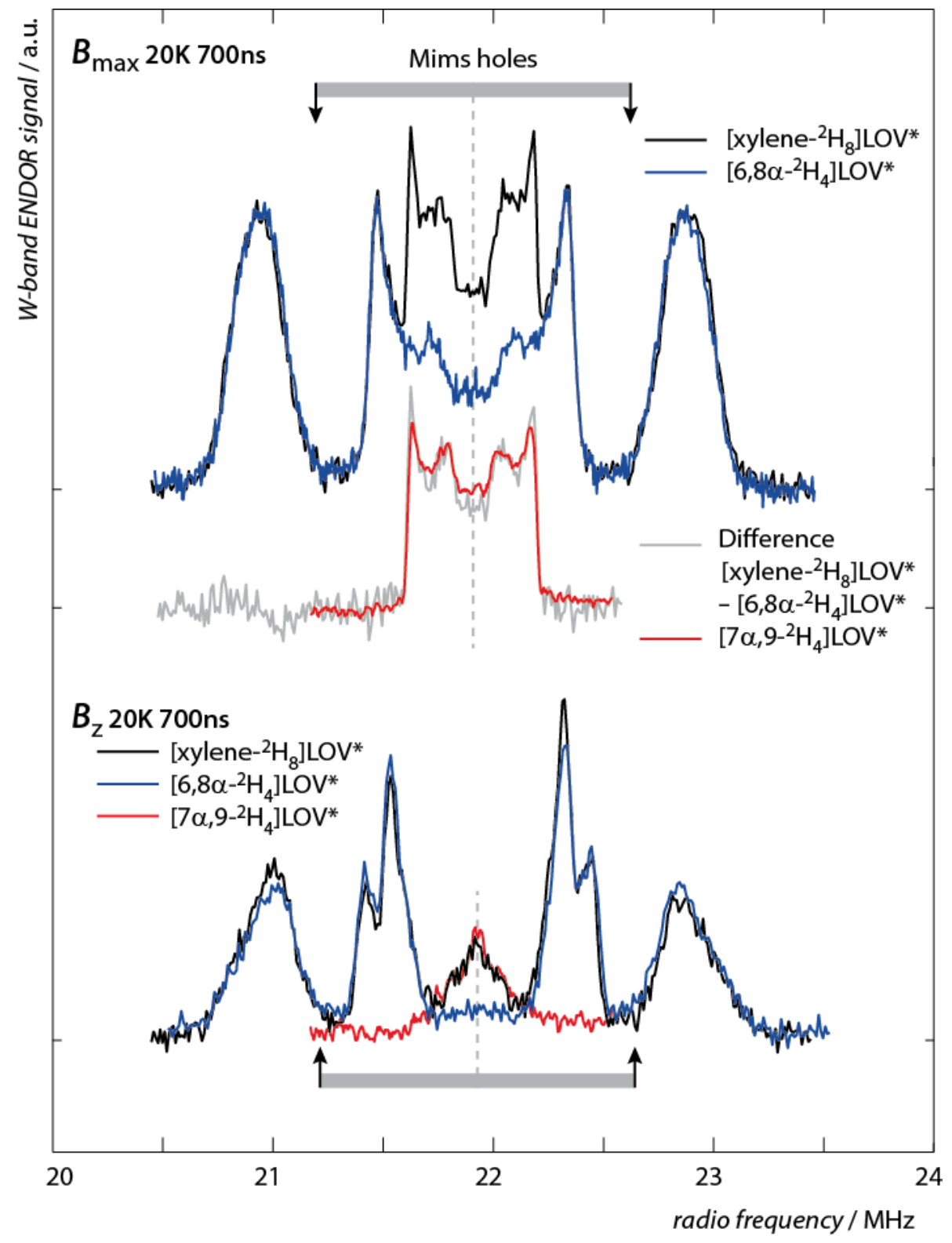

Figure S1. Pulsed W-band Mims-ENDOR spectrum of $\left[x y l e n e-{ }^{2} \mathrm{H}_{8}\right] \mathrm{LOV}^{*}$ (black), $[6,8 \alpha-$ $\left.{ }^{2} \mathrm{H}_{4}\right] \mathrm{LOV}^{*}$ (blue) and $\left[7 \alpha, 9-{ }^{2} \mathrm{H}_{4}\right] \mathrm{LOV}^{*}$ (red) recorded at $20 \mathrm{~K}$ and magnetic-field positions corresponding to $g_{\max }$ (upper panel) and $g_{x}$ (lower panel). The difference spectrum of [xylene$\left.{ }^{2} \mathrm{H}_{8}\right] \mathrm{LOV} *$ minus $\left[6,8 \alpha^{-}{ }^{2} \mathrm{H}_{4}\right] \mathrm{LOV}^{*}$ is depicted in grey. Mims holes corresponding to a $\tau$ value of 700 ns are marked with arrows. 


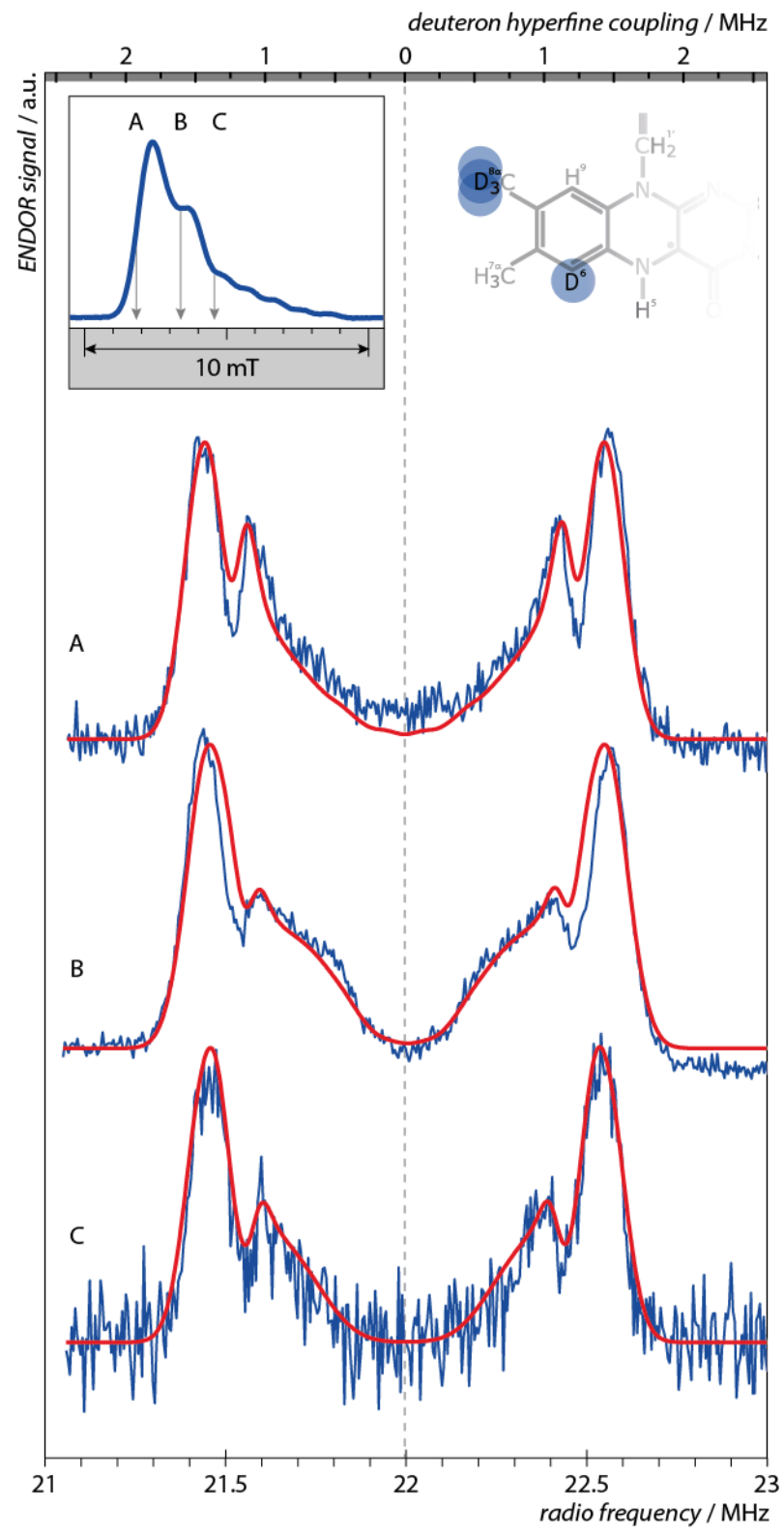

Figure S2. Pulsed W-band Mims-ENDOR spectrum of $\left[6,8 \alpha-{ }^{2} \mathrm{H}_{4}\right] \mathrm{LOV}^{*}$ recorded at indicated magnetic-field positions $(\mathrm{A}-\mathrm{C})$ at $120 \mathrm{~K}$. The respective spectral simulations of ${ }^{2} \mathrm{H}(6)$ and ${ }^{2} \mathrm{H}(8 \alpha)$ are depicted in red. 


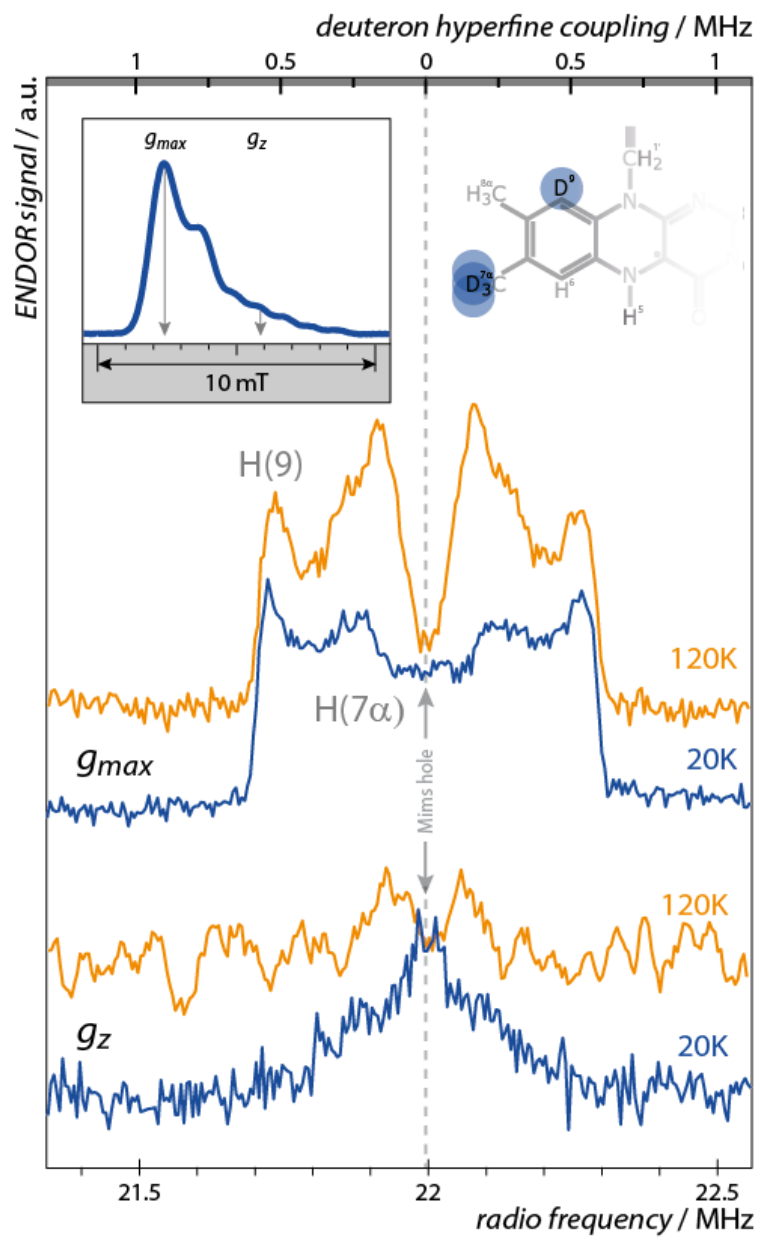

Figure S3. Pulsed W-band Mims-ENDOR spectrum of $\left[7 \alpha, 9-{ }^{2} \mathrm{H}_{4}\right] \mathrm{LOV}^{*}$ recorded at indicated magnetic-field positions at $20 \mathrm{~K}$ (blue) and $120 \mathrm{~K}$ (orange). 


\section{Specific Calculations}

1) The isoalloxazine moiety including its ribityl side chain was optimized and subsequently, the rotational barriers of both methyl groups were calculated. Different conditions were tested:

a) All nuclei except hydrogens were kept fixed, and the dihedral angle of one of the methyl groups was kept fixed at its respective energy minimum.

b) All nuclei except hydrogens and $\mathrm{C}(7 \alpha) / \mathrm{C}(8 \alpha)$ were kept fixed, and the dihedral angle of the other methyl group was kept fixed at its respective energy minimum.

c) All nuclei except hydrogens were kept fixed, and the dihedral angle of one of the methyl groups was not restricted.

d) All nuclei except hydrogens and $\mathrm{C}(7 \alpha) / \mathrm{C}(8 \alpha)$ were kept fixed, and the dihedral angle of one of the methyl groups was not restricted.

The maxima (height) of all barriers are shown in Table S1. The dihedral angle was incremented in $5^{\circ}$-steps.

Table S1: Rotational barrier heights of $7 \alpha$ and $8 \alpha$ methyl groups in riboflavin at different conditions.

\begin{tabular}{|c|l|c|}
\hline rotating methyl group & \multicolumn{1}{|c|}{ conditions } & $\Delta E_{\text {rot }}($ max $) / K$ \\
\hline $8 \alpha$ & $\begin{array}{l}7 \alpha \text { methyl group is fixed, all atoms except } \\
H \text { are fixed }\end{array}$ & 695 \\
\hline $8 \alpha$ & $\begin{array}{l}7 \alpha \text { methyl group is fixed, all atoms except } \\
H, C(7 \alpha) \text { and } C(8 \alpha) \text { are fixed }\end{array}$ & 593 \\
\hline $8 \alpha$ & $\begin{array}{l}7 \alpha \text { methyl group is free, all atoms except H } \\
\text { are fixed }\end{array}$ & 695 \\
\hline $8 \alpha$ & $\begin{array}{l}7 \alpha \text { methyl group is free, all atoms except } H, \\
C(7 \alpha) \text { and } C(8 \alpha) \text { are fixed }\end{array}$ & 593 \\
\hline $7 \alpha$ & $\begin{array}{l}8 \alpha \text { methyl group is fixed, all atoms except } \\
\mathrm{H} \text { are fixed }\end{array}$ & 728 \\
\hline $7 \alpha$ & $\begin{array}{l}8 \alpha \text { methyl group is fixed, all atoms except } \\
\mathrm{H}, \mathrm{C}(7 \alpha) \text { and } \mathrm{C}(8 \alpha) \text { are fixed }\end{array}$ & 625 \\
\hline $7 \alpha$ & $\begin{array}{l}8 \alpha \text { methyl group is free, all atoms except } \mathrm{H} \\
\text { are fixed }\end{array}$ & $\begin{array}{l}8 \alpha \text { methyl group is free, all atoms except } \mathrm{H}, \\
\mathrm{C}(7 \alpha) \text { and } \mathrm{C}(8 \alpha) \text { are fixed }\end{array}$ \\
\hline $7 \alpha$ &
\end{tabular}


2) The ribityl side chain was replaced by $\mathrm{CH}_{3}$ (lumiflavin). A full geometry optimization was applied as described above and afterwards, rotational barriers were calculated. The maxima (height) of the rotational barriers are shown in Table S2.

Table S2. Rotational barrier heights of $7 \alpha$ and $8 \alpha$ methyl groups in lumiflavin at different conditions.

\begin{tabular}{|c|l|c|}
\hline rotating methyl group & \multicolumn{1}{|c|}{ conditions } & $\Delta E_{\text {rot }}($ max $) / K$ \\
\hline $8 \alpha$ & $\begin{array}{l}7 \alpha \text { methyl group is fixed, all atoms except } \\
H \text { are fixed }\end{array}$ & 697 \\
\hline $8 \alpha$ & $\begin{array}{l}7 \alpha \text { methyl group is fixed, all atoms except } \\
H, C(7 \alpha) \text { and } C(8 \alpha) \text { are fixed }\end{array}$ & 595 \\
\hline $8 \alpha$ & $\begin{array}{l}7 \alpha \text { methyl group is free, all atoms except } \mathrm{H} \\
\text { are fixed }\end{array}$ & 697 \\
\hline $8 \alpha$ & $\begin{array}{l}7 \alpha \text { methyl group is free, all atoms except } \mathrm{H}, \\
\mathrm{C}(7 \alpha) \text { and } \mathrm{C}(8 \alpha) \text { are fixed }\end{array}$ & 594 \\
\hline $7 \alpha$ & $\begin{array}{l}8 \alpha \text { methyl group is fixed, all atoms except } \\
\mathrm{H} \text { are fixed }\end{array}$ & 720 \\
\hline $7 \alpha$ & $\begin{array}{l}8 \alpha \text { methyl group is fixed, all atoms except } \\
\mathrm{H}, \mathrm{C}(7 \alpha) \text { and } \mathrm{C}(8 \alpha) \text { are fixed }\end{array}$ & 621 \\
\hline $7 \alpha$ & $\begin{array}{l}8 \alpha \text { methyl group is free, all atoms except } \mathrm{H} \\
\text { are fixed }\end{array}$ & $\begin{array}{l}8 \alpha \text { methyl group is free, all atoms except } \mathrm{H}, \\
\mathrm{C}(7 \alpha) \text { and } \mathrm{C}(8 \alpha) \text { are fixed }\end{array}$ \\
\hline $7 \alpha$ & \multicolumn{2}{|c}{620} \\
\hline
\end{tabular}

When comparing Tables S1 and S2, it is obvious that the influence of the ribityl side chain on the barrier height is only a few Kelvin and hence, negligible. Therefore, lumiflavin was used for all subsequent calculations to minimize computation time. The dihedral angles of the rotational barriers (relaxed surface scans) for all further calculations were incremented in $3^{\circ}$ steps.

3) Several conditions of the $7 \alpha$ and $8 \alpha$ methyl group were tested to evaluate the influence of different constraints on the rotational barriers. All other conditions were kept identical as introduced in the General Procedure chapter. 
Table S3. Rotational barrier heights of the $7 \alpha$ and $8 \alpha$ methyl group in lumiflavin at different conditions.

\begin{tabular}{|c|c|c|}
\hline Rotating methyl group & Different Conditions & $\Delta E_{\text {rot }}(\max ) / K$ \\
\hline$C(8 \alpha)$ & $C(7 \alpha)$ Methyl group is fixed, all atoms (except $H$ ) are fixed & 697 \\
\hline$C(8 \alpha)$ & $\mathrm{C}(7 \alpha)$ Methyl group is fixed, all atoms (except $\mathrm{H}, \mathrm{C}(7 \alpha) \mathrm{C}(8 \alpha)$ ) are fixed & 595 \\
\hline$C(8 \alpha)$ & $\mathrm{C}(7 \alpha)$ Methyl group is fixed, all atoms (except $\mathrm{H}, \mathrm{C}(8 \alpha)$ ) are fixed & 616 \\
\hline$C(8 \alpha)$ & $\begin{array}{l}C(7 \alpha) \text { Methyl group is fixed, all atoms (except } H, C(8 \alpha) \text { ) are fixed and } C(8) \text { - } \\
C(8 \alpha) \text { Bond length fixed }\end{array}$ & 623 \\
\hline$C(8 \alpha)$ & $\begin{array}{l}C(7 \alpha) \text { Methyl group is fixed, all atoms (except } H \text { ) are fixed and } C(8)-C(8 \alpha) \\
\text { and } C(7)-C(7 \alpha) \text { Bond length fixed }\end{array}$ & 609 \\
\hline$C(8 \alpha)$ & $\mathrm{C}(7 \alpha)$ Methyl group is free, all atoms (except $\mathrm{H}$ ) are fixed & 697 \\
\hline$C(8 \alpha)$ & $\mathrm{C}(7 \alpha)$ Methyl group is free, all atoms (except $\mathrm{H}, \mathrm{C}(7 \alpha) \mathrm{C}(8 \alpha)$ ) are fixed & 594 \\
\hline$C(8 \alpha)$ & $\mathrm{C}(7 \alpha)$ Methyl group is free, all atoms (except $\mathrm{H}, \mathrm{C}(8 \alpha)$ ) are fixed & 615 \\
\hline$C(8 \alpha)$ & $\begin{array}{l}C(7 \alpha) \text { Methyl group is free, all atoms (except } H, C(8 \alpha) \text { ) are fixed and } C(8) \text { - } \\
C(8 \alpha) \text { Bond length fixed }\end{array}$ & 624 \\
\hline$C(8 \alpha)$ & $\begin{array}{l}C(7 \alpha) \text { Methyl group is free, all atoms (except } H \text { ) are fixed and } C(8)-C(8 \alpha) \\
\text { and } C(7)-C(7 \alpha) \text { Bond length fixed }\end{array}$ & 609 \\
\hline$C(7 \alpha)$ & $\mathrm{C}(8 \alpha)$ Methyl group is fixed, all atoms (except $\mathrm{H}$ ) are fixed & 720 \\
\hline$C(7 \alpha)$ & $\mathrm{C}(8 \alpha)$ Methyl group is fixed, all atoms (except $\mathrm{H}, \mathrm{C}(7 \alpha) \mathrm{C}(8 \alpha)$ ) are fixed & 621 \\
\hline$C(7 \alpha)$ & $\mathrm{C}(8 \alpha)$ Methyl group is fixed, all atoms (except $\mathrm{H}, \mathrm{C}(7 \alpha)$ ) are fixed & 641 \\
\hline$C(7 \alpha)$ & $\begin{array}{l}C(8 \alpha) \text { Methyl group is fixed, all atoms (except } \mathrm{H}, \mathrm{C}(7 \alpha) \text { ) are fixed and } \mathrm{C}(7)- \\
\mathrm{C}(7 \alpha) \text { Bond length fixed }\end{array}$ & 650 \\
\hline$C(7 \alpha)$ & $\begin{array}{l}C(8 \alpha) \text { Methyl group is fixed, all atoms (except } H \text { ) are fixed and } C(8)-C(8 \alpha) \\
\text { and } C(7)-C(7 \alpha) \text { Bond length fixed }\end{array}$ & 637 \\
\hline$C(7 \alpha)$ & $\mathrm{C}(8 \alpha)$ Methyl group is free, all atoms (except $\mathrm{H}$ ) are fixed & 720 \\
\hline$C(7 \alpha)$ & $\mathrm{C}(8 \alpha)$ Methyl group is free, all atoms (except $H, C(7 \alpha) C(8 \alpha))$ are fixed & 621 \\
\hline$C(7 \alpha)$ & $\mathrm{C}(8 \alpha)$ Methyl group is free, all atoms (except $\mathrm{H}, \mathrm{C}(8 \alpha)$ ) are fixed & 641 \\
\hline$C(7 \alpha)$ & $\begin{array}{l}\mathrm{C}(8 \alpha) \text { Methyl group is free, all atoms (except } \mathrm{H}, \mathrm{C}(8 \alpha) \text { ) are fixed and } \mathrm{C}(8) \text { - } \\
\mathrm{C}(8 \alpha) \text { Bond length fixed }\end{array}$ & 650 \\
\hline$C(7 \alpha)$ & $\begin{array}{l}C(8 \alpha) \text { Methyl group is free, all atoms (except } H \text { ) are fixed and } C(8)-C(8 \alpha) \\
\text { and } C(7)-C(7 \alpha) \text { Bond length fixed }\end{array}$ & 637 \\
\hline
\end{tabular}


Table S3 clearly shows that the rotational barrier of the $7 \alpha$ methyl group is slightly higher than that of the $8 \alpha$ methyl group. Additionally, it is obvious that the height of the rotational barrier is significantly influenced by the selected conditions.

4) Next, the direct interaction between the two methyl groups was analyzed in greater detail.

One of the methyl groups was replaced by hydrogen and a full geometry optimization was applied. Afterwards, the rotational barrier of the other methyl group was calculated for different conditions. All other conditions were as already introduced in the General Procedure chapter.

Table S4. Rotational barrier heights of the $7 \alpha$ and $8 \alpha$ methyl groups in lumiflavin at different conditions, if one of the methyl groups was replaced by hydrogen.

\begin{tabular}{|c|c|c|}
\hline rotating methyl group & conditions & $\Delta E_{\text {rot }}(\max ) / K$ \\
\hline $8 \alpha$ & $\begin{array}{l}7 \alpha \text { methyl group replaced by hydrogen / all atoms (except } H \\
\text { and } C(8 \alpha) \text { ) are fixed }\end{array}$ & $\sim 17$ \\
\hline $8 \alpha$ & $\begin{array}{l}7 \alpha \text { methyl group replaced by hydrogen / all atoms (except } \\
\text { H) are fixed }\end{array}$ & $\sim 17$ \\
\hline $8 \alpha$ & $\begin{array}{l}7 \alpha \text { methyl group replaced by hydrogen / all atoms (except } H \\
\text { and } C(8 \alpha) \text { ) are fixed } C(7)-C(7 \alpha) \text { bond length is fix }\end{array}$ & $\sim 17$ \\
\hline $7 \alpha$ & $\begin{array}{l}8 \alpha \text { methyl group replaced by hydrogen / all atoms (except } H \\
\text { and } C(7 \alpha) \text { ) are fixed }\end{array}$ & $\sim 11$ \\
\hline $7 \alpha$ & $\begin{array}{l}8 \alpha \text { methyl group replaced by hydrogen / all atoms (except } \\
\text { H) are fixed }\end{array}$ & $\sim 25$ \\
\hline $7 \alpha$ & $\begin{array}{l}8 \alpha \text { methyl group replaced by hydrogen / all atoms (except } \mathrm{H} \\
\text { and } C(8 \alpha) \text { ) are fixed } C(8)-C(8 \alpha) \text { bond length is fix }\end{array}$ & $\sim 11$ \\
\hline
\end{tabular}

The comparison of Tables S3 and S4 clearly shows a strong breakdown of the rotational barrier, if one methyl group has been replaced by hydrogen. The effect is depicted as Figure S4. 

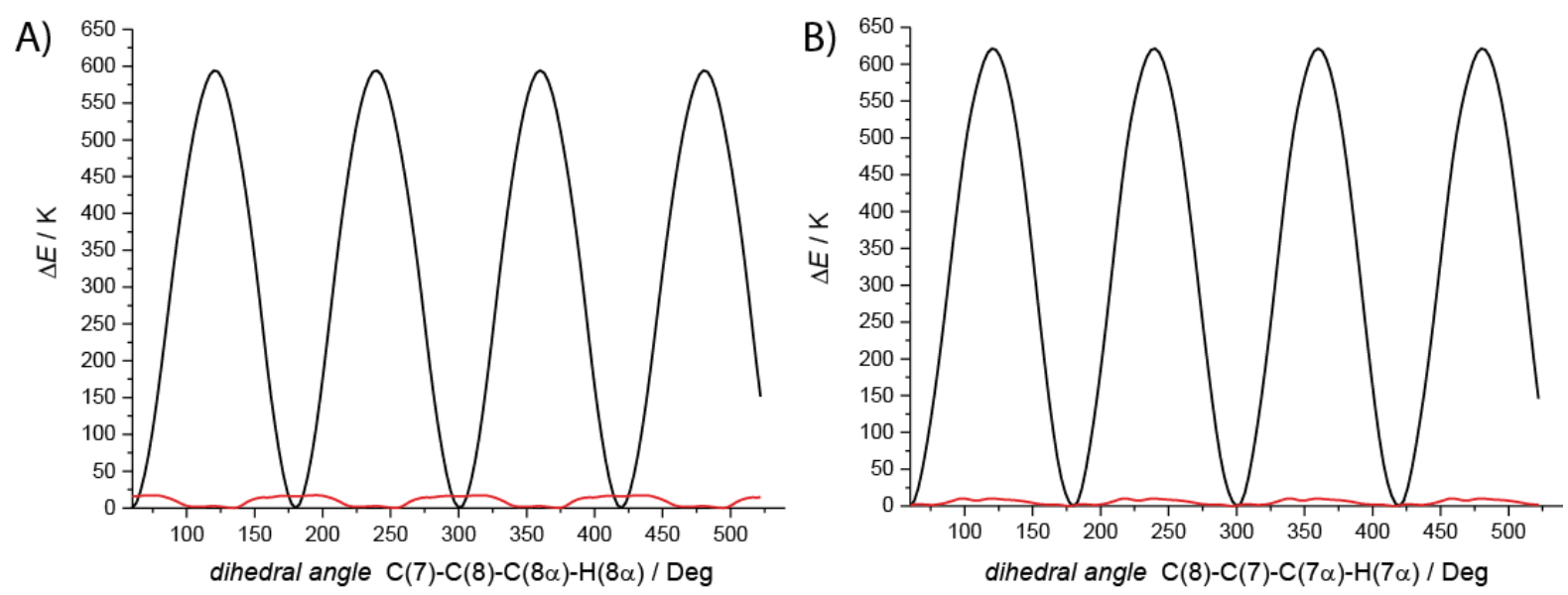

Figure S4. A) Rotational barrier of the $8 \alpha$ methyl group (black), if $\mathrm{C}(7 \alpha), \mathrm{C}(8 \alpha)$ and all hydrogens were allowed to relax. Rotational barrier of the $8 \alpha$ methyl group, if the $7 \alpha$ methyl group has been replaced by hydrogen, and $\mathrm{C}(8 \alpha)$ and all hydrogens were allowed to relax (red). B) Rotational barrier of the $7 \alpha$ methyl group, if $\mathrm{C}(7 \alpha), \mathrm{C}(8 \alpha)$ and all hydrogens were allowed to relax (black). Rotational barrier of the $7 \alpha$ methyl group if the $8 \alpha$ methyl group has been replaced by hydrogen, and $\mathrm{C}(7 \alpha)$ and all hydrogens were allowed to relax (red).

Since the dominant influence on the height of the $8 \alpha$ methyl group rotational barrier is the $7 \alpha$ methyl group, different variations of the $7 \alpha$ methyl group were applied to evaluate its effect in more detail.

5) The rotational barriers of the $8 \alpha$ methyl group were calculated for different $\mathrm{C}(7 \alpha)-\mathrm{H}(7 \alpha)$ bond lengths. All three bond lengths of $\mathrm{C}(7 \alpha)-\mathrm{H}(7 \alpha)$ were set to the same value and constrained for the relaxed surface scan. The bond lengths were varied from 102 to $118 \mathrm{pm}$ in 2-pm-steps. All other conditions were identical as introduced in chapter General Procedure. Four different conditions were tested (see below). 
A)

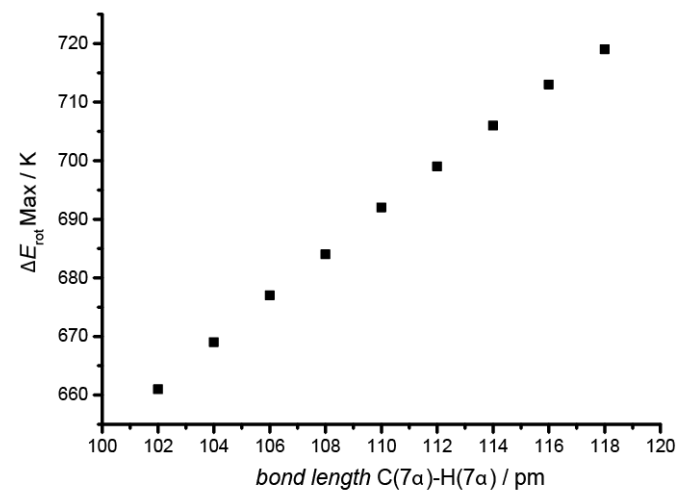

C)

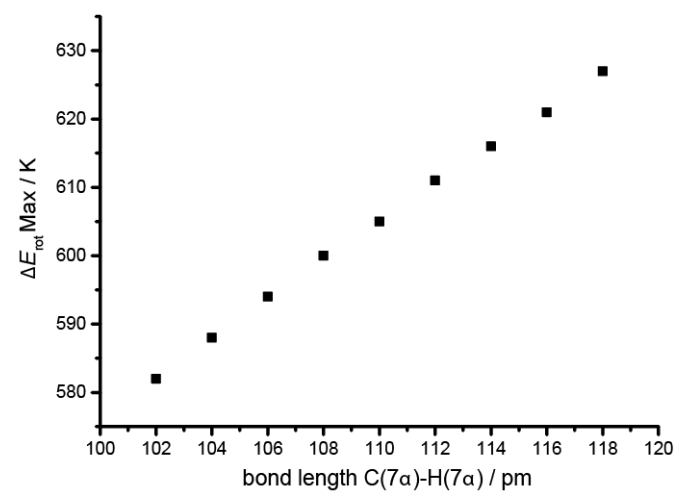

B)

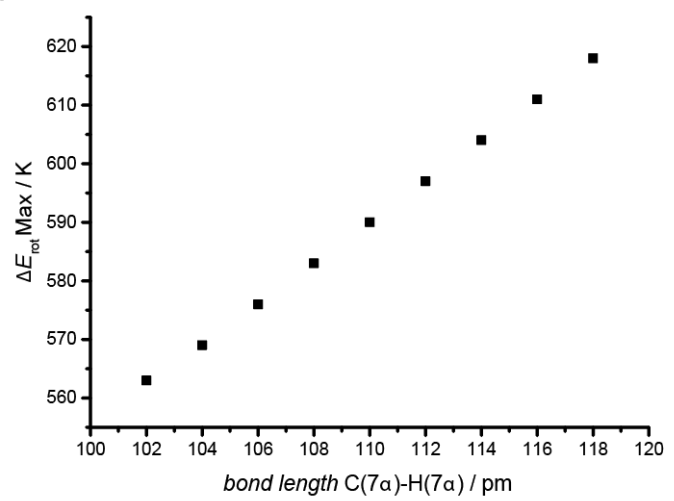

D)

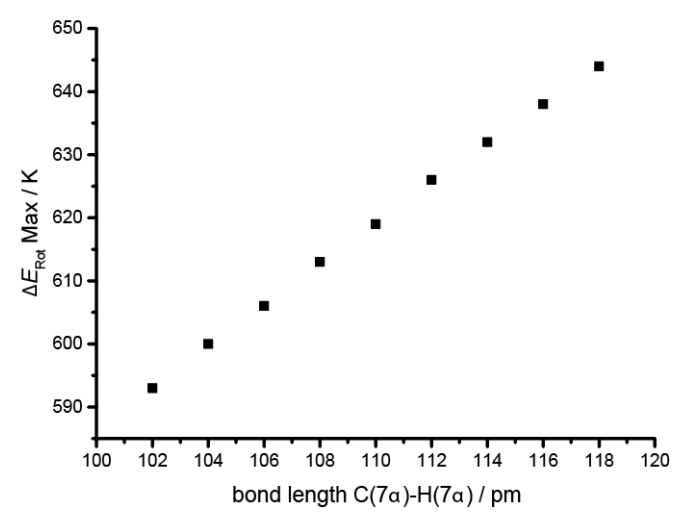

Figure S5. Rotational barrier height of the $8 \alpha$ methyl group as a function of the $\mathrm{C}(7 \alpha)-\mathrm{H}(7 \alpha)$ bond length. A) All hydrogens were allowed to relax. B) All hydrogens, $\mathrm{C}(7 \alpha)$ and $\mathrm{C}(8 \alpha)$ were allowed to relax. C) All hydrogens, $\mathrm{C}(7 \alpha)$ and $\mathrm{C}(8 \alpha)$ were allowed to relax, but the $\mathrm{C}(7)-\mathrm{C}(7 \alpha)$ and $\mathrm{C}(8)-\mathrm{C}(8 \alpha)$ bond length were kept fixed. D) All hydrogens and $\mathrm{C}(8 \alpha)$ were allowed to relax, but the $\mathrm{C}(8)-\mathrm{C}(8 \alpha)$ bond length was fixed.

6) The rotational barriers of the $8 \alpha$ methyl group were calculated for different fixed dihedral angles of the $7 \alpha$ methyl group given by the atoms $\mathrm{C}(8)-\mathrm{C}(7)-\mathrm{C}(7 \alpha)-\mathrm{H}(7 \alpha)$. A relaxed surface scan was applied for given fixed dihedral angle of the $7 \alpha$ methyl group. The dihedral angle of the $7 \alpha$ methyl group was incremented from $0^{\circ}$ to $150^{\circ}$ in $10^{\circ}$-steps. All other conditions were identical as introduced in chapter General Procedure. In Figure S6 the effects of the $\mathrm{C}(8)-\mathrm{C}(7)-\mathrm{C}(7 \alpha)-\mathrm{H}(7 \alpha)$ dihedral angle on the height of the $8 \alpha$ rotational barrier are depicted for four different conditions. 
A)

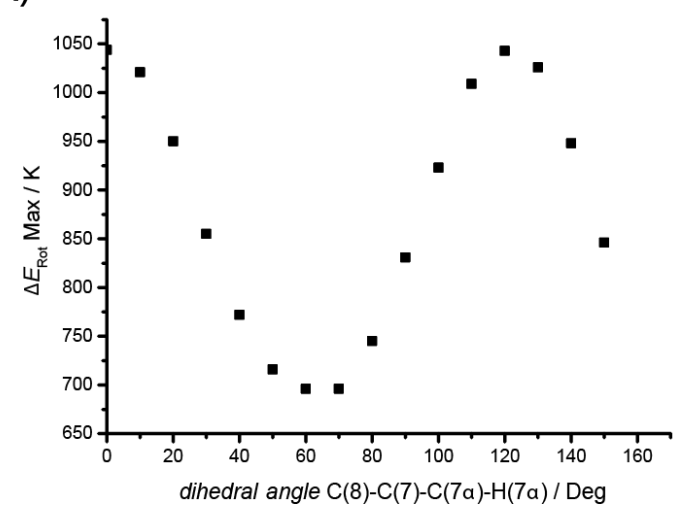

C)

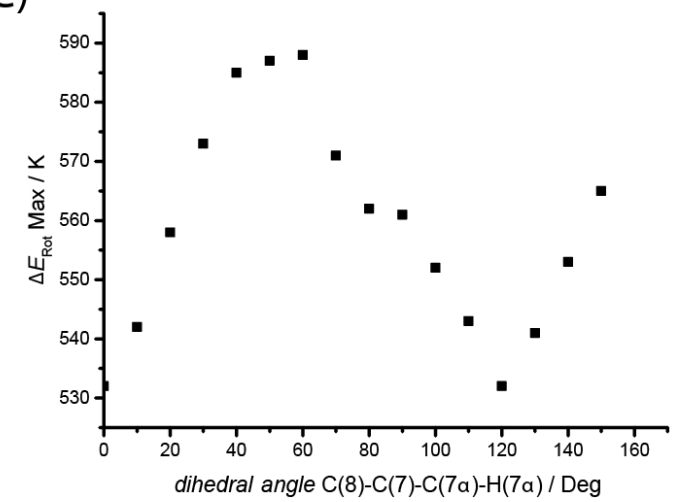

B)

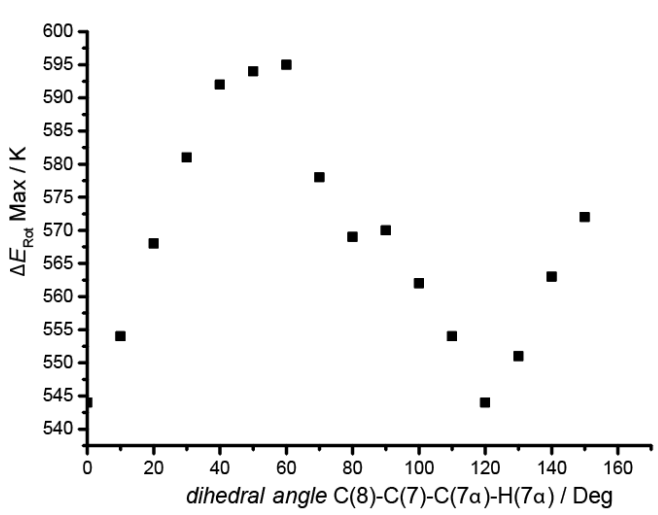

D)

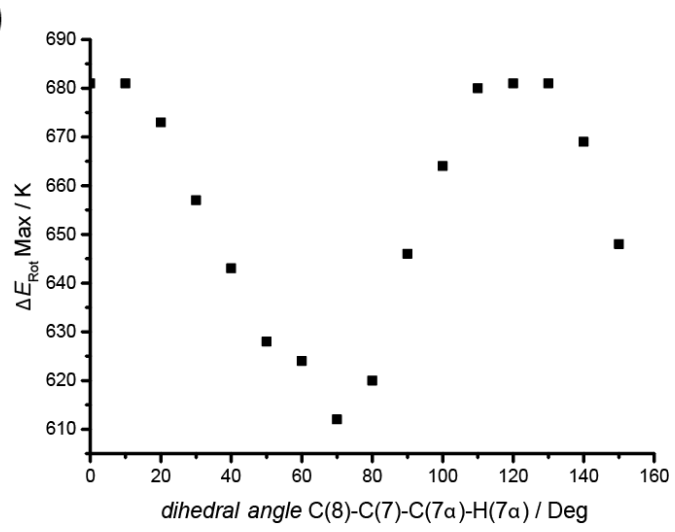

Figure S6. Rotational barrier heights of the $8 \alpha$ methyl group as a function of the $\mathrm{C}(8)-\mathrm{C}(7)-$ $\mathrm{C}(7 \alpha)-\mathrm{H}(7 \alpha)$ dihedral angle. A) All hydrogens were allowed to relax. B) All hydrogens, $\mathrm{C}(7 \alpha)$ and $\mathrm{C}(8 \alpha)$ were allowed to relax. $C)$ All hydrogens, $\mathrm{C}(7 \alpha)$ and $(\mathrm{C} 8 \alpha)$ were allowed to relax, but the $\mathrm{C}(7)-\mathrm{C}(7 \alpha)$ and $\mathrm{C}(8)-\mathrm{C}(8 \alpha)$ bond lengths were fixed. D) All hydrogens and $\mathrm{C}(8 \alpha)$ were allowed to relax, but the $\mathrm{C}(8)-\mathrm{C}(8 \alpha)$ bond length was fixed.

7) The rotational barriers of the $8 \alpha$ methyl group were calculated for different fixed bond angles of the $\mathrm{C}(7 \alpha)$ atom given by the atoms $\mathrm{C}(8)-\mathrm{C}(7)-\mathrm{C}(7 \alpha)$. The relaxed surface scan was applied for given fixed bond angle of the $\mathrm{C}(7 \alpha)$ atom. The bond angle of the $\mathrm{C}(7 \alpha)$ atom was incremented from $101^{\circ}$ to $141^{\circ}$ in $4^{\circ}$-steps. The bond angle of the optimized geometry is $121.1^{\circ}$. All other conditions were identical as introduced in chapter General Procedure. In Figure S7 the effects of the $\mathrm{C}(8)-\mathrm{C}(7)-\mathrm{C}(7 \alpha)-\mathrm{H}(7 \alpha)$ dihedral angle on the height of the $8 \alpha$ rotational barrier are depicted for two different conditions. 

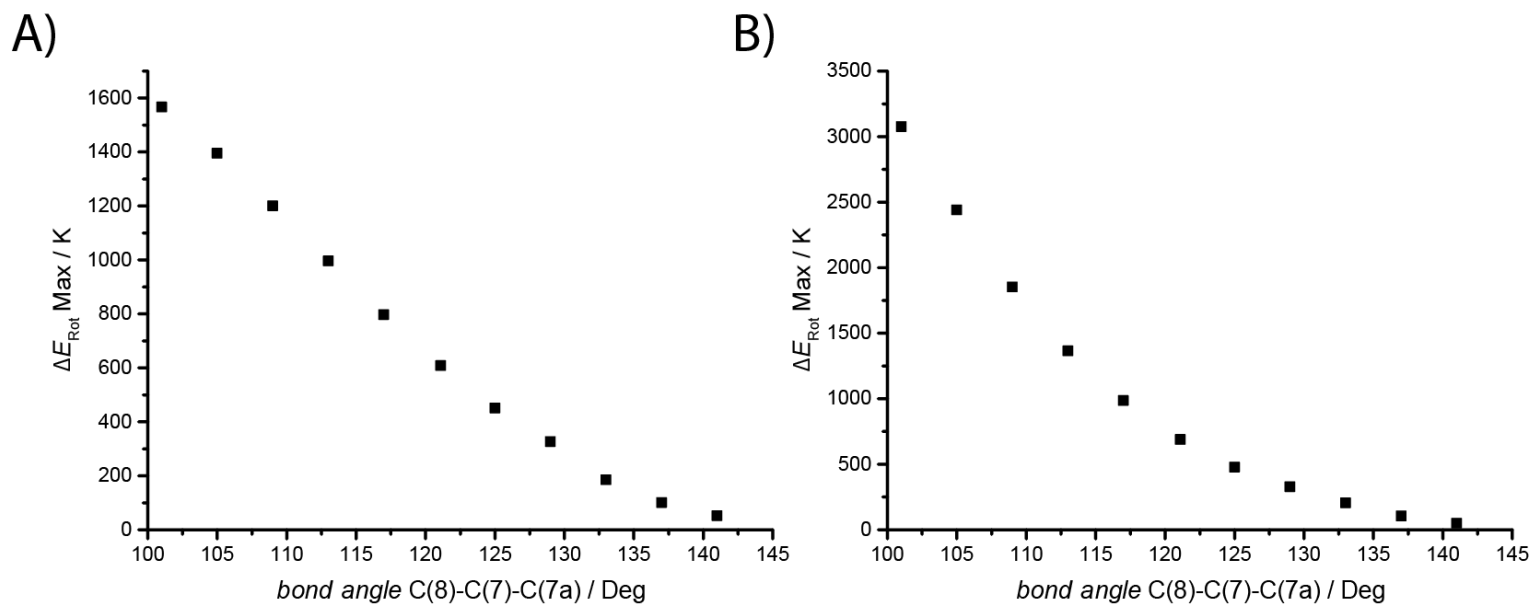

Figure S7. Rotational barrier height of the $8 \alpha$ methyl group as a function of the $\mathrm{C}(8)-\mathrm{C}(7)-$ $\mathrm{C}(7 \alpha)$ bond angle. A) All hydrogens, $\mathrm{C}(7 \alpha)$ and $\mathrm{C}(8 \alpha)$ were allowed to relax. B) All hydrogens and $\mathrm{C}(7 \alpha)$ were allowed to relax. 


\section{C) Supporting information for the synthesis of deuterated riboflavins}

\section{Preparation of $\left[6,7 \alpha, 8 \alpha, 9-{ }^{2} \mathrm{H}_{8}\right]$ riboflavin}

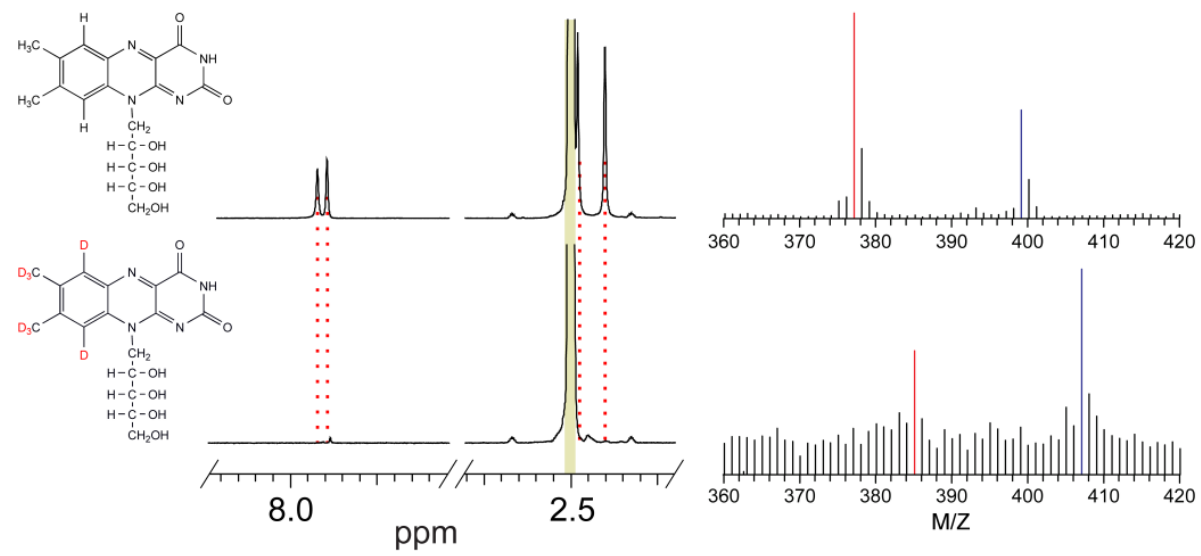

Figure S8. NMR and mass spectra of unlabeled riboflavin (top) and synthesized [6,7 $\alpha, 8 \alpha, 9-$ ${ }^{2} \mathrm{H}_{8}$ ]riboflavin (bottom). The labeling pattern of riboflavin is shown in the left part, ${ }^{1} \mathrm{H}-\mathrm{NMR}$ spectra are shown in the middle part, FAB mass spectra are shown in the right part. Red lines in the mass spectrum indicate $[\mathrm{M}+\mathrm{H}]^{+}$signal, blue lines indicate $[\mathrm{M}+\mathrm{Na}]^{+}$signal.

\section{Preparation of $\left[7 \alpha, 9-{ }^{2} \mathrm{H}_{4}\right]$ riboflavin}

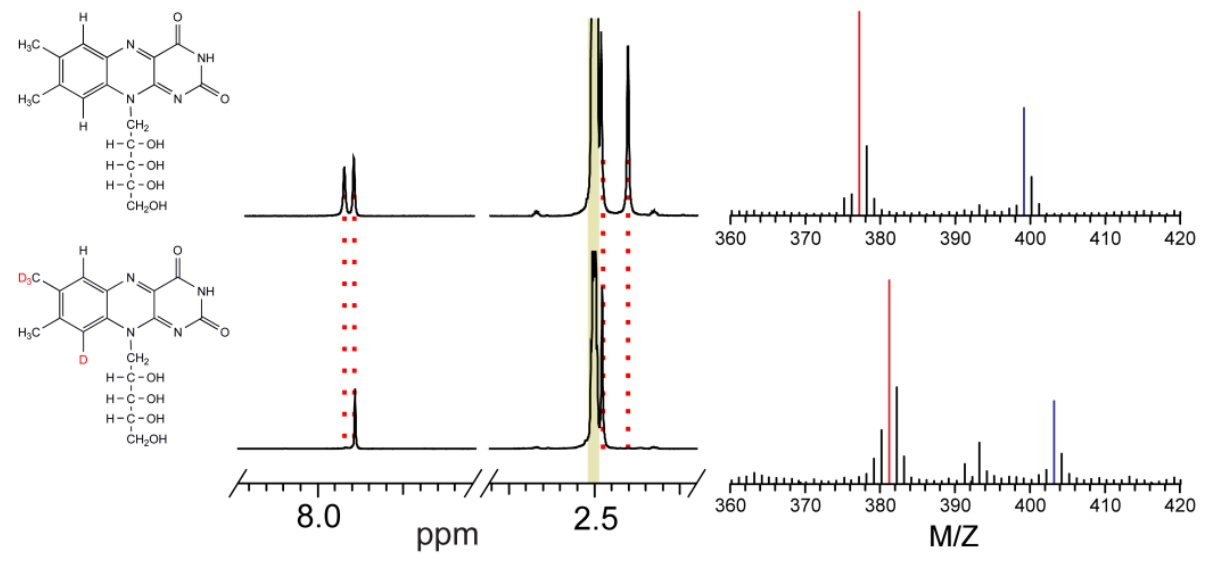

Figure S9. NMR and mass spectra of unlabeled riboflavin (top) and synthetized [7 $\alpha, 9$ ${ }^{2} \mathrm{H}_{4}$ ]riboflavin (bottom). The labeling pattern of riboflavin is shown in the left part, ${ }^{1} \mathrm{H}-\mathrm{NMR}$ spectra are shown in the middle part, FAB mass spectra are shown in the right part. Red lines in mass spectra indicate $[\mathrm{M}+\mathrm{H}]^{+}$signal and blue lines indicate $[\mathrm{M}+\mathrm{Na}]^{+}$signal. 
Preparation of $\left[6,8 \alpha-{ }^{2} \mathrm{H}_{4}\right]$ riboflavin
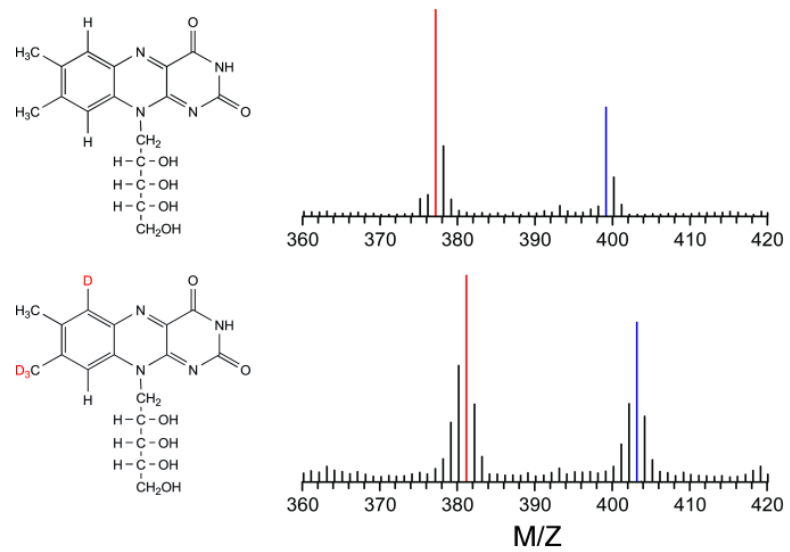

Figure S10. Mass spectra of unlabeled riboflavin (top) and $\left[6,8 \alpha-{ }^{2} \mathrm{H}_{4}\right]$ riboflavin (bottom). The labeling pattern of riboflavin is shown in the left part, FAB mass spectra are shown in the right part. Red lines in mass spectrum indicate $[\mathrm{M}+\mathrm{H}]^{+}$signal and blue lines indicate $[\mathrm{M}+\mathrm{Na}]^{+}$ signal.

Table S5. FAD mass spectrometry data of riboflavin isotopologues (M/Z).

\begin{tabular}{c|rrrc}
\hline & riboflavin & $\begin{array}{c}{\left[7 \alpha, 9-{ }^{2} \mathrm{H}_{4}\right]} \\
\text { riboflavin }\end{array}$ & $\begin{array}{l}{\left[6,8 \alpha-{ }^{2} \mathrm{H}_{4}\right]} \\
\text { riboflavin }\end{array}$ & $\begin{array}{l}{\left[6,7 \alpha, 8 \alpha, 9-{ }^{2} \mathrm{H}_{8}\right]} \\
\text { riboflavin }\end{array}$ \\
\hline$[\mathrm{M}+\mathrm{H}]^{+}$ & 377.2 & 381.2 & 381.2 & 385.1 \\
{$[\mathrm{M}+\mathrm{Na}]^{+}$} & 399.2 & 403.2 & 403.2 & 407.1 \\
$\begin{array}{c}\text { Molecular } \\
\text { mass }\end{array}$ & 376.2 & 380.2 & 380.2 & 384.1 \\
\hline
\end{tabular}


Table S6. ${ }^{1} \mathrm{H}-\mathrm{NMR}$ chemical shifts of riboflavin isotopologues. Internal standard is DMSO (2.5 ppm).

\begin{tabular}{|c|c|c|c|c|c|c|}
\hline \multirow{2}{*}{ H position } & \multicolumn{2}{|c|}{ Riboflavin } & \multicolumn{2}{|c|}{$\left[7 \alpha, 9-{ }^{2} \mathrm{H}_{4}\right]$ riboflavin } & \multicolumn{2}{|c|}{$\begin{array}{l}{[6,7 \alpha, 8 \alpha, 9-} \\
\left.{ }^{2} \mathrm{H}_{8}\right] \text { riboflavin }\end{array}$} \\
\hline & ppm & Integration & ppm & Integration & $\mathrm{ppm}$ & Integration \\
\hline $7 \alpha$ & 2.39 & 2.74 & - & & - & \\
\hline $8 \alpha$ & 2.47 & 3.00 & 2.48 & 3.19 & - & \\
\hline 5 & 3.46 & 1.05 & 3.46 & 1.28 & 3.49 & 1.01 \\
\hline 3', 4', 5'a & 3.64 & 3.01 & 3.63 & 3.50 & 3.63 & 2.77 \\
\hline $2^{\prime}$ & 4.26 & 1.00 & 4.26 & 1.24 & 4.24 & 1.01 \\
\hline 5'-OH & 4.47 & 1.00 & 4.48 & 0.84 & - & \\
\hline 1'a & 4.62 & 0.95 & 4.62 & 1.20 & 4.63 & 0.96 \\
\hline 2'-OH & 4.79 & 1.00 & 4.79 & 0.86 & - & \\
\hline 4'-OH & 4.8 & 1.01 & 4.86 & 0.82 & - & \\
\hline 1'b & 4.92 & 0.96 & 4.93 & 1.21 & 4.91 & 1.05 \\
\hline 3'-OH & 5.10 & 1.00 & 5.11 & 0.82 & & \\
\hline 6 & 7.86 & 0.99 & 7.86 & 1.00 & - & \\
\hline 9 & 7.90 & 1.00 & - & & - & \\
\hline 3 & 11.32 & 0.95 & 11.30 & 0.81 & - & \\
\hline
\end{tabular}




\section{References}

1. Neese, F., The ORCA program system. WIREs Computational Molecular Science 2012, 2, 73-78.

2. Becke, A. D., Density-functional exchange-energy approximation with correct asymptotic behavior. Physical Review A 1988, 38, 3098-3100.

3. Vosko, S. H.; Wilk, L.; Nusair, M., Accurate spin-dependent electron liquid correlation energies for local spin density calculations: a critical analysis. Canadian Journal of Physics 1980, 58, 1200-1211.

4. Perdew, J. P., Density-functional approximation for the correlation energy of the inhomogeneous electron gas. Physical Review B 1986, 33, 8822-8824.

5. Weigend, F.; Ahlrichs, R., Balanced basis sets of split valence, triple zeta valence and quadruple zeta valence quality for $\mathrm{H}$ to $\mathrm{Rn}$ : design and assessment of accuracy. Physical Chemistry Chemical Physics 2005, 7, 3297-3305.

6. Barone, V., Structure, magnetic properties and reactivities of open-shell species from density functional and self-consistent hybrid methods. In Recent Advances in Density-Functional Methods, Chong, D. P., Ed. World Scientific Publishing: Singapore, 1996; Vol. 1, pp 287-334. 7. Lee, C.; Yang, W.; Parr, R. G., Development of the Colle-Salvetti correlation-energy formula into a functional of the electron density. Physical Review B 1988, 37, 785-789.

8. Becke, A. D., Density-functional thermochemistry. III. The role of exact exchange. Journal of Chemical Physics 1993, 98, 5648-5652.

9. Schäfer, A.; Horn, H.; Ahlrichs, R., Fully optimized contracted Gaussian basis sets for atoms Li to Kr. Journal of Chemical Physics 1992, 97, 2571-2577. 